\title{
Hemodialysis crossover study using a relative blood volume change-guided ultrafiltration control compared with standard hemodialysis: the BV-UFC study
}

Susumu Ookawara ${ }^{1 * \dagger}$, Kiyonori Ito ${ }^{1 \dagger}$, Takayuki Uchida ${ }^{2}$, Keito Tokuyama ${ }^{3}$, Satoshi Kiryu ${ }^{4}$, Takeshi Suganuma ${ }^{5}$, Kyoko Hojyo ${ }^{6}$, Haruhisa Miyazawa', Yuichiro Ueda ${ }^{1}$, Chiharu Ito $^{7}$, Osamu limura ${ }^{8}$, Kunihiko Yoshiya ${ }^{9}$,

Yoshiyuki Morishita ${ }^{1}$, Norio Hanafusa ${ }^{10}$ and Kaoru Tabei ${ }^{11}$

\begin{abstract}
Background: It has been difficult to sufficiently achieve body-fluid management using blood volume (BV) monitor during hemodialysis (HD) with constant ultrafiltration (UF) rate. Recently, a relative BV change-guided UF control (BV-UFC) system was developed by combining the concepts of an automatic feedback system that could control the UF rate and profile with real- time monitoring of relative changes in BV (\% $\triangle B V$ ). However, this system has limited application in the clinical setting. Therefore, in this study, we aimed to perform the crossover study on HD with BV-UFC compared to standard HD in terms of hemodynamic stability during HD.

Methods: Forty-eight patients entered an 8-week crossover period of standard HD or HD with BV-UFC. Prevalence of intradialytic hypotension (IDH) as a primary outcome and changes in blood pressure (BP), differences in $\% \triangle B V$, and achievement of the target ultrafiltration volume as secondary outcomes were compared. IDH was defined as a reduction in systolic BP $\geq 20 \mathrm{mmHg}$ from the baseline value at $10 \mathrm{~min}$ after HD initiation.
\end{abstract}

Results: No significant differences were found in the prevalence of IDH, frequency of intervention for symptomatic $\mathrm{IDH}$, and achievement of the target ultrafiltration volume between the groups. The $\% \Delta B V$ was significantly fewer $(-12.1 \pm 4.8 \%$ vs. $-14.4 \pm 5.2 \%, p<0.001)$ in the HD with BV-UFC than that in the standard HD.

Conclusions: HD with BV-UFC did not reduce the prevalence of IDH compared with standard HD. The relief of a relative BV reduction at the end of HD may be beneficial in patients undergoing HD with BV-UFC.

Trial Registration: UMIN, UMIN000024670. Registered on December 1, 2016.

Keywords: Automatic feedback system using blood volume monitoring, Hemodialysis, Blood pressure drop, Relative changes in blood volume, Ultrafiltration

\footnotetext{
* Correspondence: su-ooka@hb.tp1.j

†Susumu Ookawara and Kiyonori Ito contributed equally to this work.

'Division of Nephrology, First Department of Integrated Medicine, Saitama

Medical Center, Jichi Medical University, 1-847 Amanuma-cho, Omiya-ku,

Saitama 330-8503, Japan

Full list of author information is available at the end of the article
}

(c) The Author(s). 2020 Open Access This article is licensed under a Creative Commons Attribution 4.0 International License, which permits use, sharing, adaptation, distribution and reproduction in any medium or format, as long as you give appropriate credit to the original author(s) and the source, provide a link to the Creative Commons licence, and indicate if changes were made. The images or other third party material in this article are included in the article's Creative Commons licence, unless indicated otherwise in a credit line to the material. If material is not included in the article's Creative Commons licence and your intended use is not permitted by statutory regulation or exceeds the permitted use, you will need to obtain permission directly from the copyright holder. To view a copy of this licence, visit http://creativecommons.org/licenses/by/4.0/ The Creative Commons Public Domain Dedication waiver (http://creativecommons.org/publicdomain/zero/1.0/) applies to the data made available in this article, unless otherwise stated in a credit line to the data. 


\section{Introduction}

Excessive body- fluid removal has been known to result in intradialytic hypotension (IDH) through the impairment of plasma refilling from the interstitium to the capillary circulation [1]. This event is more likely to occur at the late phase of hemodialysis (HD) [2], mainly due to the development of hemodynamic instability associated with ultrafiltration (UF)- induced blood volume (BV) reduction. Conversely, fluid overload with insufficient fluid removal during HD is associated with hypertension and left ventricular hypertrophy [3, 4]. Both IDH and fluid overload with insufficient intradialytic fluid management were reported to be associated with increased mortality $[5,6]$. Therefore, to prevent body- fluid management failure during $\mathrm{HD}, \mathrm{BV}$ monitoring systems that could evaluate relative changes in $\mathrm{BV}(\% \triangle B V)$ during $\mathrm{HD}$ have been developed [7-11]. However, it has been difficult to sufficiently achieve body- fluid management using a BV monitor during HD with a constant UF rate [12].

Controlling the UF profile is one of the maneuvers used to maintain hemodynamic stability during HD, in which the UF rate is gradually decreased after starting $\mathrm{HD}$ at a high rate, to induce increase in plasma refilling [13-16]. Recently, a relative BV change- guided UF control (BV-UFC) system (Nikkiso, Tokyo, Japan) was developed for HD therapy by combining the concepts of an automatic feedback system that could control the UF rate and profile with real- time monitoring of $\% \triangle B V$ during HD. However, thus far, this system has limited application in the clinical setting of HD therapy. Therefore, in this study, we aimed to perform the crossover study on HD with BV-UFC compared to standard HD in terms of hemodynamic stability, including the prevalence of IDH, as a primary outcome, and changes in blood pressure (BP), differences in $\% \Delta B V$, and achievement of the target UF volume (UFV) at the end of HD as secondary outcomes.

\section{Materials and methods Study design}

This study was registered at the University Hospital Medical Information Network (study No. UMIN000024670, date of registration: December 1, 2016) in Japanese Primary Registry Network; approved by the institutional review board of Saitama Medical Center, Jichi Medical University, Japan (RINS 16-003); the study was conducted in accordance with the Declaration of Helsinki (2004 Tokyo revision). All patients signed informed consent forms before participation.

We designed a 12-week prospective, crossover, intervention study, which included the first and second HD sessions but excluded the third, to compare HD with BV-UFC and standard HD at a constant UF rate for the management of body- fluid status in patients undergoing
HD. In this study, all of the third HD session were performed using standard HD. Prior to this study, we could not judge if the reliability of HD with BV-UFC would be able to reach the dry weight or not to delay the achievement of the target UFV at the end of HD. It would be important to strictly manage the body- fluid status at the third HD session because HD therapy was not performed for 2 days after the third HD session. Therefore, we performed the session using standard HD, which could reliably achieve dry weight at the third HD session in each patient. Patient recruitment was performed from December 1, 2016 to June 30, 2017 and this study was conducted between December 1, 2016 and September 30, 2017 in our medical center and four other hospitals in Japan.

\section{Patients}

Patients undergoing HD who met the following criteria were enrolled: (i) age $\geq 18$ years; (ii) started HD at least 3 months before the study; (iii) undergoing HD 3 times weekly at $4 \mathrm{~h}$ per session; (iv) had a BV reduction induced by UF during HD; and (v) had a serum albumin level $\geq 3.0 \mathrm{~g} / \mathrm{dL}$ before study enrollment. The exclusion criteria were as follows: cardiovascular disease with hemodynamic instability including congestive heart failure, myocardial infarction, and unstable angina pectoris; severe cerebrovascular disease; cognitive impairment; use of antihypotensive medication during HD; and existence of vascular access recirculation.

\section{Definitions}

During HD, BP was measured using an electronic sphygmomanometer at several timepoints, as follows: HD initiation, initiation of BV monitoring (10 min after HD initiation; BP baseline), and hourly during HD. IDH was defined as a reduction in systolic $\mathrm{BP} \geq 20 \mathrm{mmHg}$ from the baseline value [17-19]. The interventions for symptomatic IDH, which is accompanied with nausea, dizziness, and cramps, included prompt change of the dialysis bed (Trendelenburg position), oxygen inhalation, and infusion of saline.

\section{Monitoring of $\% \triangle B V$ values during $\mathrm{HD}$}

Relative BV reduction during HD, measured using a BV monitor mounted on the dialysis equipment (DCS100NX; Nikkiso, Tokyo, Japan), was evaluated as $\% \triangle B V$ from $10 \mathrm{~min}$ after HD initiation to the end of HD in each patient, as previously described [11].

\section{Run-in period}

The setting of dry weight in each faculty was performed using some kinds of dry weight setting methods, including physical findings, hemodynamic status during HD, cardiothoracic ratio measured by chest X-ray, measurement 
of inferior vena cava diameter, and the degree in $\% \triangle B V$ reduction. To adequately reach the dry weight in $\mathrm{HD}$ with BV-UFC, the increase in UF rate in the second part of HD compared with the constant UF rate and values of $\% \triangle B V$ at the end of the automatic UF rate- adjustment period with BV-UFC were determined within a 4-week run-in period in each enrolled patient and were not changed throughout crossover study period (Fig. 1).

\section{Crossover study period}

During this period, UF was performed under standard HD or HD with BV-UFC (Fig.1). Data collection was performed in the first and second HD sessions for each therapy in a cross-over manner. The third HD session was performed using standard HD to successfully achieve the target body weight at the end of HD and was excluded from the analysis. During an 8-week period, each participant was crossed over between standard HD and HD with BV-UFC as the first and second HD sessions without any change in dry weight.

\section{UF rate setting during HD with the BV-UFC system}

$\mathrm{HD}$ with the BV-UFC system was divided into four parts according to changes in the UF rate during the HD session (Fig. 2). First, from HD initiation to $10 \mathrm{~min}$, the UF rate was set as a constant (constant UF rate period), and calculated as body weight gain $(\mathrm{kg}) / 4 \mathrm{~h}$, similar to that in standard HD. Second, the UF rate was set as 1.2-1.5 times higher than that in the first part for the next
60 min of HD (higher UF rate period). Third, the UF rate was automatically adjusted to match the $\% \Delta B V$, which was set to values ranging from $-3 \%$ to $-6 \%$ at the end of this part, for the next 150 min (automatic UF rate-adjustment period). $\% \Delta B V$ was set to decrease curvilinearly during this part in this study. That is, the degree in $\% \Delta B V$ reduction was set to reach $50 \%$ in the first quarter, $80 \%$ in the second quarter and $95 \%$ in the third quarter of the automatic UF rate-adjustment period. Finally, the UF rate was automatically determined as a constant rate to reach the dry weight at the end of HD (automatic constant UF rate period) in response to the residual bodyfluid excess at the end of the third part. The changes in the UF rate in standard HD and HD with BV-UFC are shown in Fig. 2. In HD with BV-UFC, the UF rates in the second part were $1.35 \pm 0.06$ times $(0.95$ $\pm 0.27 \mathrm{~L} / \mathrm{h}$ ) higher than those in the first part, indicating a significant increase (UF rate in the first part: $0.72 \pm 0.21 \mathrm{~L} / \mathrm{h}, p<0.001)$. However, compared with those in the first part, the UF rates were significantly suppressed from $140 \mathrm{~min}$ after HD initiation to the end of HD $(p<0.001)$. To confirm precision of the sample mean in the UF rate during HD, the standard error of the mean was calculated. In standard HD, the standard error in the UF rate was $0.01 \mathrm{~L} / \mathrm{h}$ throughout the HD session, and in HD with BV-UFC, ranged from $0.01 \mathrm{~L} / \mathrm{h}$ to $0.02 \mathrm{~L} / \mathrm{h}$, which were considered small values in each group.

\section{2-week study period}

\begin{tabular}{|l|l|}
\hline 4-week run-in period & 8-week crossover study period \\
\hline
\end{tabular}

\begin{tabular}{|c|c|}
\hline \multicolumn{2}{|c|}{ Determinations } \\
\hline & $\begin{array}{l}\text { Increase in the UF rate during } \\
\text { the higher UF rate period than } \\
\text { the constant UF rate }\end{array}$ \\
\hline & $\begin{array}{l}\% \triangle B V \text { value at the end of the } \\
\text { automated UF rate-adjustment } \\
\text { period in } \mathrm{HD} \text { with } \mathrm{BV} \text {-UFC }\end{array}$ \\
\hline
\end{tabular}

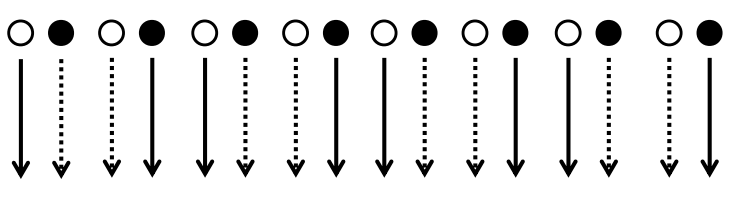

First HD session in a weekly HD schedule

Second HD session in a weekly HD schedule

(Third HD session was not included in this study)

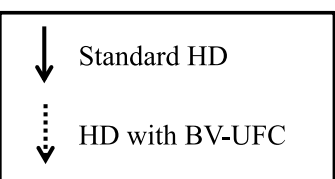

Fig. 1 Flow diagram of the BV-UFC study. HD, hemodialysis; UF, ultrafiltration, BV-UFC, blood volume change-guided ultrafiltration control, \% $\triangle B V$, relative blood volume change 


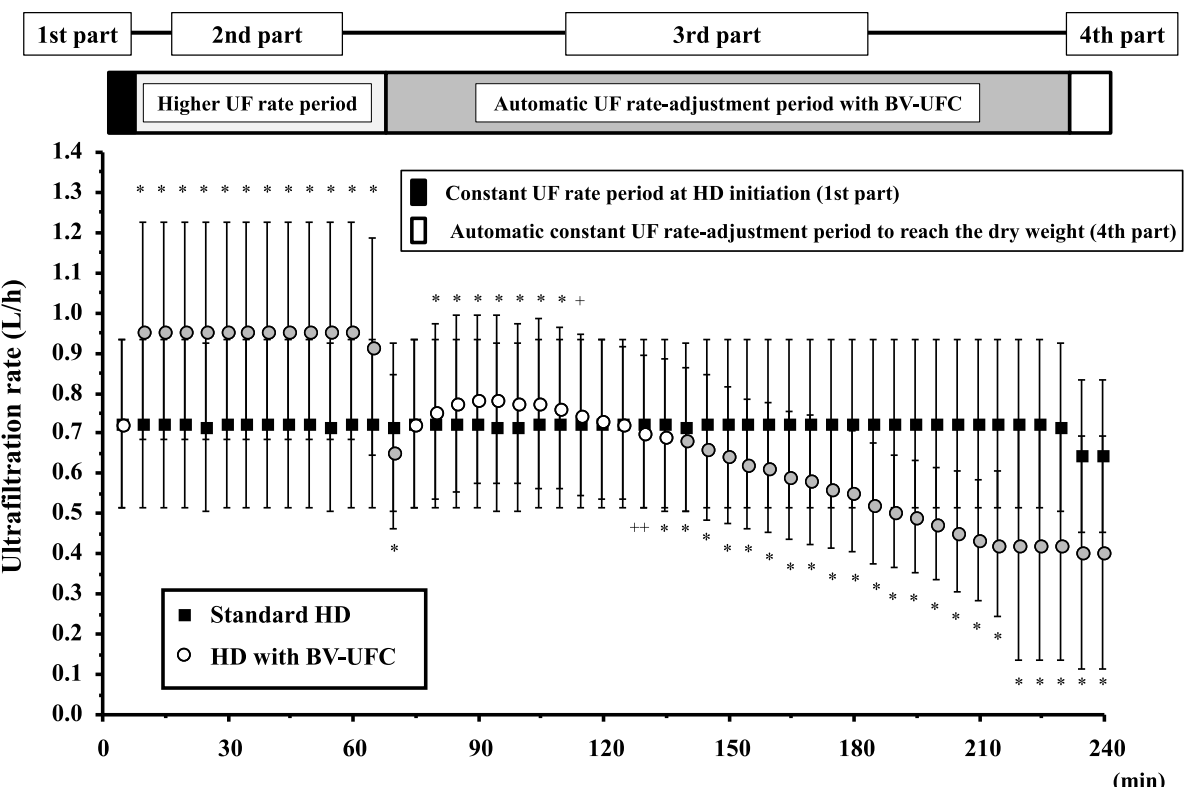

Fig. 2 Changes in ultrafiltration rate in HD with BV-UFC in comparison with the constant UF rate in standard HD. $\mathrm{O}$ Gray circle $p<0.001$ versus $\mathrm{HD}$ initiation in $\mathrm{HD}$ with $\mathrm{BV}-\mathrm{UFC},{ }^{*} p<0.001$ versus standard $\mathrm{HD},+p<0.01$ versus standard $\mathrm{HD},++p<0.05$ versus standard $\mathrm{HD}, \mathrm{HD}$, hemodialysis; UF, ultrafiltration, BV-UFC, blood volume change- guided ultrafiltration control

\section{Outcome}

The primary outcome was the prevalence of IDH during HD. The secondary outcomes were episodes of interventions for symptomatic IDH, changes in intradialytic BP, $\% \triangle B V$ at the end of HD, and achievement of the target UFV during HD in each patient.

\section{Statistical analyses}

Data are presented as the mean \pm standard deviation. Student's t-tests for paired values were used for the comparison of clinical parameters between standard HD and $\mathrm{HD}$ with $\mathrm{BV}$-UFC. The $\% \triangle B V$ values and UF rate changes in each group during HD were evaluated using repeated-measures analysis of variance with general linear models and Tukey tests. Chi-squared tests were used to assess the comparisons of IDH prevalence, the number of patients with IDH, episodes of interventions for symptomatic IDH, the number of patients with symptomatic IDH, and achievement of the target UFV at the end of HD, complemented by an adjusted residual analysis. All analyses were performed using IBM SPSS Statistics version19.0 for Windows (SPSS Inc., Chicago, IL, USA). A $p$ value of $<0.05$ was considered statistically significant.

\section{Results}

Baseline characteristics

Of the 75 patients screened, 64 met the inclusion criteria and were enrolled in this study. Overall, 16 patients did not complete the study because of lack of data $(n=12)$ and withdrawal from the study $(\mathrm{n}=4)$ and were excluded from the analysis (Fig. 3). Therefore, 48 patients completed the study. The patients' general characteristics are summarized in Table 1 . No significant differences in the UFV, systolic and diastolic BP measurements, heart rate, and Kt/V urea between standard HD and HD with BV-UFC were found in this study. Furthermore, 40 patients $(83.3 \%)$ took antihypertensive medication, and 26 patients $(54.2 \%)$ took it before the HD session.

\section{Primary outcome: prevalence of IDH during HD}

IDH was recognized in 197 (51.3\%) HD sessions in standard HD and 198 (51.6\%) HD sessions in HD with

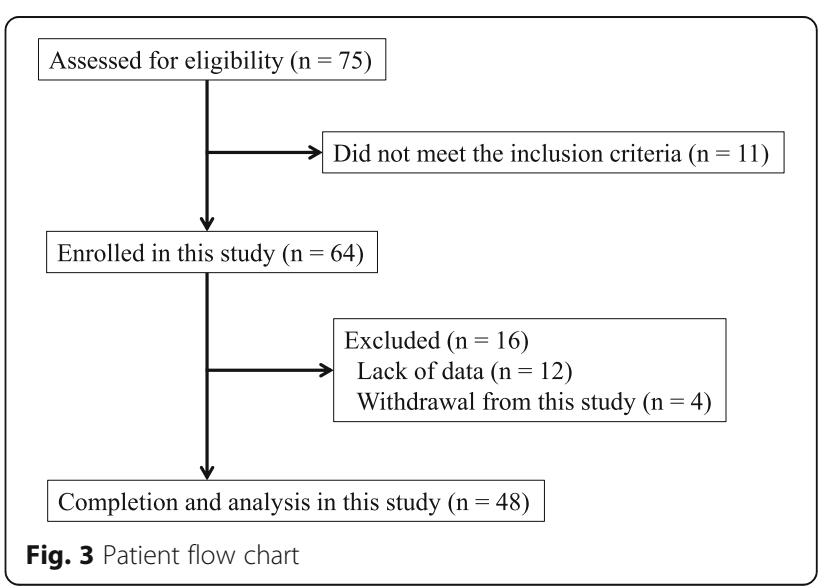


Table 1 Patients' general characteristics

\begin{tabular}{|c|c|c|c|}
\hline & \multicolumn{3}{|c|}{ Characteristics at study initiation } \\
\hline Number of patients (men/women) & \multicolumn{2}{|l|}{$48(15 / 33)$} & \\
\hline Age (years) & \multicolumn{2}{|l|}{$64.2 \pm 7.3$} & \\
\hline HD duration (years) & \multicolumn{2}{|l|}{$7.5 \pm 7.3$} & \\
\hline Dry weight (kg) & \multicolumn{2}{|l|}{$61.3 \pm 15.7$} & \\
\hline \multicolumn{4}{|l|}{ Disease } \\
\hline Diabetes mellitus & \multicolumn{2}{|l|}{19} & \\
\hline Chronic glomerulonephritis & \multicolumn{2}{|l|}{12} & \\
\hline Nephrosclerosis & \multicolumn{2}{|l|}{3} & \\
\hline ADPKD & \multicolumn{2}{|l|}{6} & \\
\hline Others & \multicolumn{2}{|l|}{8} & \\
\hline \multicolumn{4}{|l|}{ Comorbidities } \\
\hline Cardiovascular disease & \multicolumn{2}{|l|}{$0 / 48$} & \\
\hline Cerebrovascular disease & \multicolumn{2}{|l|}{$4 / 48$} & \\
\hline \multicolumn{4}{|l|}{ Medication, $n(\%)$} \\
\hline Antihypertensive medicines & \multicolumn{2}{|l|}{$40(83.3)$} & \\
\hline Renin-angiotensin system blocker & \multicolumn{2}{|l|}{$31(64.6)$} & \\
\hline Calcium channel blocker & \multicolumn{2}{|l|}{$33(68.8)$} & \\
\hline Beta blocker & \multicolumn{2}{|l|}{$12(25.0)$} & \\
\hline Alpha blocker & \multicolumn{2}{|l|}{$8(16.7)$} & \\
\hline Vitamin D analogue & \multicolumn{2}{|l|}{$39(79.6)$} & \\
\hline Phosphate binder & \multicolumn{2}{|l|}{$41(85.4)$} & \\
\hline Erythropoiesis-stimulating agent & \multicolumn{2}{|l|}{$46(95.8)$} & \\
\hline \multicolumn{4}{|l|}{ Laboratory findings } \\
\hline $\mathrm{Hb}(\mathrm{g} / \mathrm{dL})$ & \multicolumn{2}{|l|}{$10.9 \pm 0.8$} & \\
\hline BUN (mg/dL) & \multicolumn{2}{|l|}{$67.4 \pm 15.5$} & \\
\hline Serum creatinine (mg/dL) & \multicolumn{2}{|l|}{$11.3 \pm 2.3$} & \\
\hline $\mathrm{Na}(\mathrm{mEq} / \mathrm{L})$ & $138.7 \pm 1.7$ & & \\
\hline $\mathrm{K}(\mathrm{mEq} / \mathrm{L})$ & $5.0 \pm 0.7$ & & \\
\hline $\mathrm{Cl}(\mathrm{mEq} / \mathrm{L})$ & $104.1 \pm 2.7$ & & \\
\hline $\mathrm{Ca}(\mathrm{mg} / \mathrm{dL})$ & $8.7 \pm 0.6$ & & \\
\hline$P(m g / d L)$ & $5.4 \pm 1.3$ & & \\
\hline Total protein (g/dL) & $6.4 \pm 0.4$ & & \\
\hline Serum albumin (g/dL) & $3.7 \pm 0.3$ & & \\
\hline & Standard HD & HD with BV-UFC & $p$-value \\
\hline n (total number of HD sessions) & 384 & 384 & \\
\hline Ultrafiltration (L/session) & $2.80 \pm 0.84$ & $2.79 \pm 0.80$ & 0.780 \\
\hline Systolic blood pressure (mmHg) & $151 \pm 19$ & $151 \pm 19$ & 0.933 \\
\hline Diastolic blood pressure (mmHg) & $80 \pm 11$ & $80 \pm 12$ & 0.158 \\
\hline Heart rate (beats/min) & $69.3 \pm 9.3$ & $69.8 \pm 10.1$ & 0.093 \\
\hline $\mathrm{Kt} / \mathrm{N}$ urea & $1.45 \pm 0.25$ & $1.48 \pm 0.24$ & 0.720 \\
\hline
\end{tabular}

$H D$ hemodialysis, ADPKD autosomal dominant polycystic kidney disease, $H b$ hemoglobin, $B U N$ blood urea nitrogen, $B V$-UFC blood volume change- guided ultrafiltration control 
BV-UFC. No significant difference in IDH prevalence was found between the groups $(p=0.942$, Fig.4). In standard HD, the number of patients who had episodes of IDH was 44 patients, and the number of IDH episodes in each patient with IDH during this study was 4.5 \pm 2.4 times, whereas in HD with BV-UFC, the number of patients who had episodes of IDH was 43 patients, and the number of IDH episodes in each patient with IDH was $4.6 \pm 2.4$ times. There were no significant differences in the number of patients who had IDH episodes $(p=0.726)$ and in the number of IDH episodes in each patient with IDH $(p=0.804)$ between the groups.

\section{Secondary outcomes}

\section{Episodes of interventions for symptomatic IDH}

The episodes of intervention for symptomatic IDH was recognized in 15 (3.9\%) HD sessions in standard HD and 17 (4.4\%) HD sessions in HD with BV-UFC. In standard HD, the intervention included 9 sessions of saline infusion and 6 sessions of change from the supine position to the Trendelenburg position. In HD with BVUFC, the intervention also included 9 sessions of saline infusion and 8 sessions of change to the Trendelenburg position. No significant difference in those for symptomatic IDH was found between the groups $(p=0.718)$. In standard HD, the number of patients who had episodes of symptomatic IDH was 9 patients, and the number of symptomatic IDH episodes in each symptomatic IDH patient was $1.6 \pm 1.0$ times, whereas in HD with BVUFC, the number of patients who had episodes of symptomatic IDH was 9 patients, and those of symptomatic IDH episodes in each symptomatic IDH patient was 1.9 \pm 1.1 times. There was no significant difference in the number of symptomatic IDH episodes $(p=0.653)$ between the groups. However, there was a significant difference in the distribution of timing of the intervention for symptomatic IDH episodes during HD between the groups $(\mathrm{p}=0.022$, Fig. 5), i.e., the number of the

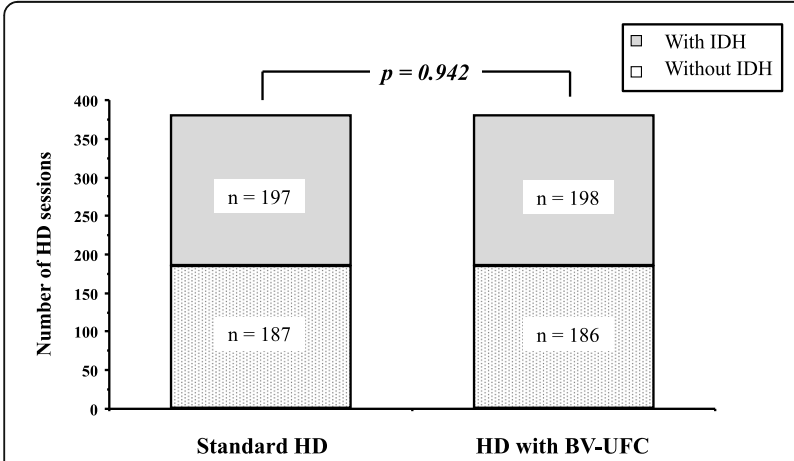

Fig. 4 Comparison of the prevalence of IDH during HD between standard HD and HD with BV-UFC. HD, hemodialysis; IDH, intradialytic hypotension, BV-UFC, blood volume change- guided ultrafiltration control interventions for symptomatic IDH episodes in HD with BV-UFC during 2 to $3 \mathrm{~h}$ HD session was significantly higher than those in standard HD $(p<0.01)$, whereas the number of those in standard HD during the last $1 \mathrm{~h}$ HD session was significantly higher than those in HD with BV-UFC $(p<0.05)$.

\section{Changes in intradialytic BP}

In standard $\mathrm{HD}$, the systolic BP from $2 \mathrm{~h}$ after HD initiation to the end significantly decreased compared with the $\mathrm{BP}$ at baseline $(p<0.001$; Table 2$)$. The systolic BP at the end also significantly decreased compared with the values $3 \mathrm{~h}$ after HD initiation $(p<0.05)$. In $\mathrm{HD}$ with $\mathrm{BV}$ UFC, the systolic BP from $1 \mathrm{~h}$ after HD initiation to the end significantly decreased compared with the baseline BP ( $p<0.01$ vs. $1 \mathrm{~h}$ after HD initiation; and $p<0.001$ vs. others). However, the difference in systolic BP between $3 \mathrm{~h}$ and the end of HD was not significant $(p=0.955)$. There were no differences in diastolic BP in standard HD, whereas little but significant differences in diastolic BP in HD with BV-UFC were confirmed at 2 and $3 \mathrm{~h}$ after HD (both $p<$ 0.05 vs. HD initiation). However, these differences in diastolic BP disappeared at the end of $\mathrm{HD}$ in $\mathrm{HD}$ with BVUFC.

\section{$\% \triangle B V$ at the end of $H D$}

The $\% \triangle B V$ in HD with BV-UFC significantly decreased from 15 to 180 min compared with that in standard HD ( $p<0.05$ vs. $180 \mathrm{~min}$; and $p<0.001$ vs. others), whereas the $\% \triangle B V$ in standard HD significantly decreased from 200 min to the end compared with that in HD with BVUFC ( $p<0.05$ vs. $200 \mathrm{~min}$; and $p<0.001$ vs. others). Finally, at the end of $\mathrm{HD}$, the decrease in $\% \triangle B V$ in $\mathrm{HD}$ with BV-UFC was significantly fewer than that in standard HD $(-12.1 \pm 4.8 \%$ vs. $-14.4 \pm 5.2 \%, p<0.001$, Fig. 6$)$. Furthermore, to confirm precision of the sample mean in $\% \triangle B V$ monitoring during $\mathrm{HD}$, the standard error of the mean was calculated. In standard HD, the standard error in $\% \triangle B V$ ranged from $0.02 \%$ to $0.3 \%$, and in $\mathrm{HD}$ with BV-UFC, ranged from $0.03 \%$ to $0.3 \%$, which were considered relatively small values in each group.

\section{Achievement of the target UFV during HD}

In this study, achievement of the target UFV at the end of $\mathrm{HD}$ was defined as within $\pm 0.3 \mathrm{~kg}$ of the dry weight. The target UFV was not achieved in 3 of the $384 \mathrm{HD}$ sessions in standard HD and 5 of the 384 HD sessions in HD with BV-UFC. No significant difference in the achievement of the target UFV at the end of HD was found between the groups $(p=0.722)$.

\section{Discussion}

IDH has been mainly associated with a BV reduction, which is induced by UF over a short period, and 


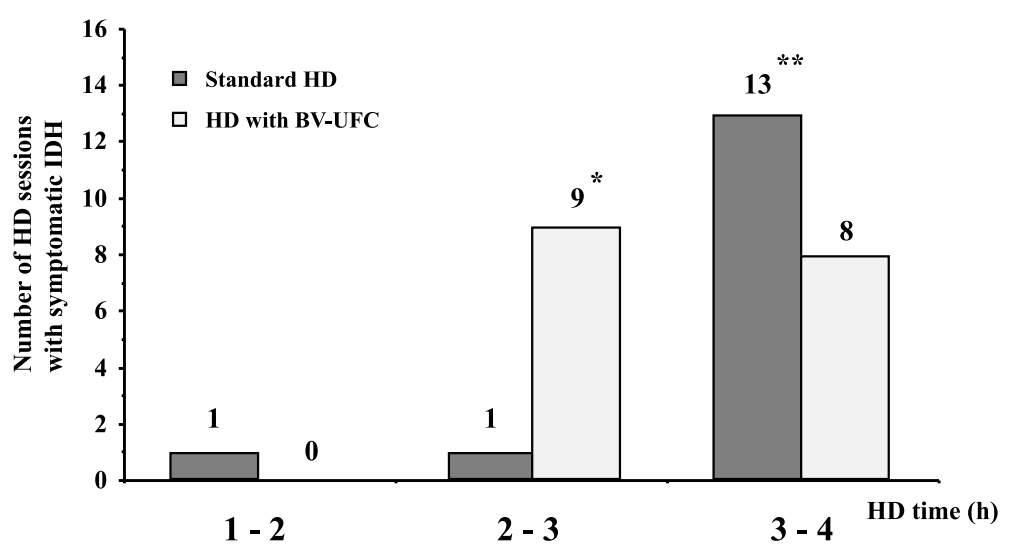

Fig. 5 Comparison of interventional episodes for symptomatic IDH divided into the time of occurrence during HD between standard HD and HD with BV-UFC. ${ }^{*} p<0.05$ versus standard HD, ${ }^{* *} p<0.01$ versus HD with BV-UFC, HD, hemodialysis; IDH, intradialytic hypotension, BV-UFC, blood volume change- guided ultrafiltration control

impaired cardiovascular compensatory mechanisms in patients undergoing HD [17, 20]. Recently, the prevalence of IDH, which was defined as a decrease in systolic $\mathrm{BP} \geq 20 \mathrm{mmHg}$, reached $63.8-68.9 \%$, and interventions were implemented in $8.5-9.6 \%$ of standard HD sessions $[5,17]$. In this study, the prevalence of IDH was nearly $50 \%$ and approximately $4 \%$ for symptomatic IDH interventions in both $H D$ with BV-UFC and standard HD. Therefore, it can be presumed that there are no significant differences between HD with BV-UFC and standard HD in terms of hemodynamic stability during HD. The effect of automatic feedback systems that could control the UF rate in response to the relative changes in BV during HD have been reported to be useful in preventing the occurrence of IDH [21-23]. However, this system was also recently reported not to reduce the rate of symptomatic IDH events [24] and the degree of systolic $\mathrm{BP}$ reduction [25], and the present study could not confirm the effect of this system on IDH prevention. A potential reason for why this system did not reduce the prevalence of IDH was the limit of accuracy in BV monitoring itself including the suitability of $\% \triangle B V$ during HD [26]. In addition, patients were prioritized based on hemodynamic stability in this study and there would be possible to include the patients who systemic BP was relatively high before HD. Furthermore, in addition to the use of antihypertensive medicines in 40 patients out of 48 patients in this study, 26 patients took these agents before HD, which was possible to influence the BP decrease after HD initiation. Therefore, these might be the reasons that IDH was frequently confirmed after HD initiation.

In the present study, a difference in $\% \triangle B V$ at the end of HD could be significantly confirmed between standard HD and HD with BV-UFC. The $\% \triangle B V$ decreased linearly in standard HD, as previously reported [27, 28], from $30 \mathrm{~min}$ after HD initiation to the end, and the value reached $-14.4 \pm 5.2 \%$. Meanwhile, in HD with BVUFC, according to the gradual decrease of UF rate during the automatic UF rate- adjustment period, the slope of $\mathrm{BV}$ reduction became small compared with that in standard $\mathrm{HD}$; therefore, the $\% \triangle B V$ values at the end of

Table 2 Comparisons of systolic BP and diastolic BP between standard HD and HD with BV-UFC

\begin{tabular}{|c|c|c|c|c|c|}
\hline & BP baseline & $1 \mathrm{~h}$ & $2 \mathrm{~h}$ & $3 \mathrm{~h}$ & End of $\mathrm{HD}$ \\
\hline \multicolumn{6}{|l|}{ Systolic BP (mmHg) } \\
\hline Standard HD & $151 \pm 19$ & $148 \pm 18$ & $145 \pm 17^{*}$ & $144 \pm 17^{*}$ & $140 \pm 17^{*, * *}$ \\
\hline HD with BV-UFC & $151 \pm 19$ & $146 \pm 19^{\# \#}$ & $143 \pm 19^{\#}$ & $140 \pm 19^{\#}$ & $139 \pm 19^{\#}$ \\
\hline \multicolumn{6}{|l|}{ Diastolic BP (mmHg) } \\
\hline Standard HD & $80 \pm 11$ & $78 \pm 11$ & $78 \pm 11$ & $78 \pm 10$ & $79 \pm 10$ \\
\hline HD with BV-UFC & $80 \pm 12$ & $78 \pm 11$ & $78 \pm 11^{\$}$ & $78 \pm 11^{\$}$ & $78 \pm 11$ \\
\hline
\end{tabular}

* $p<0.001$ versus HD initiation in standard HD

** $p<0.05$ versus $3 \mathrm{~h}$ after HD initiation in standard HD

$\# p<0.001$ versus HD initiation in HD with BV-UFC

$\#$ \# $p<0.01$ versus HD initiation in HD with BV-UFC

$\$ p<0.05$ versus $\mathrm{HD}$ initiation in HD with BV-UFC

$B P$ blood pressure, $H D$ hemodialysis, $B V$-UFC blood volume change- guided ultrafiltration control 


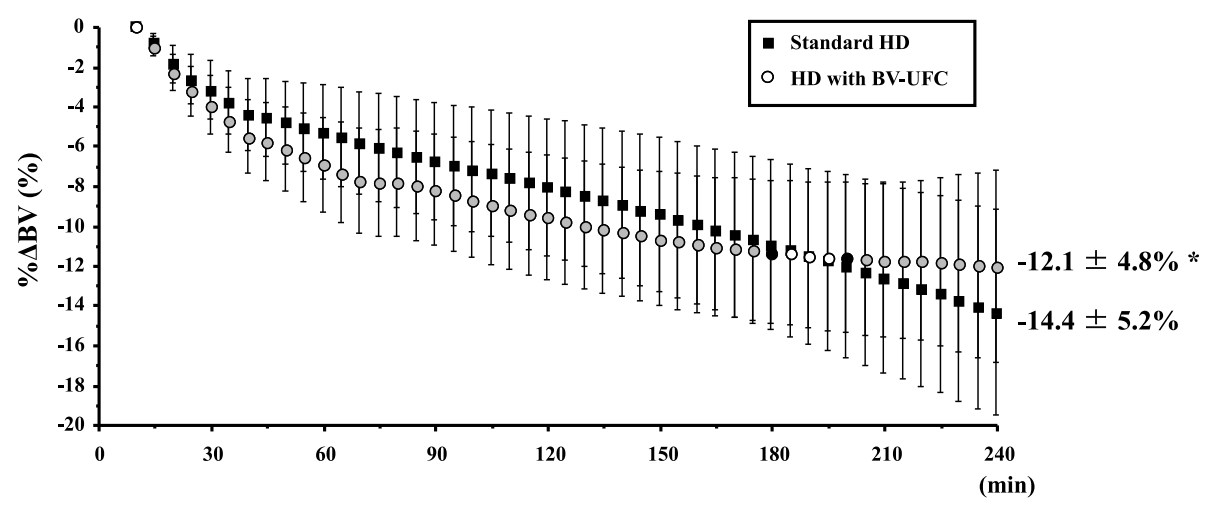

Fig. 6 Comparison of \% $\triangle B V$ in HD with BV-UFC and the constant rate of ultrafiltration in standard HD. $\bullet p<0.05$ versus standard HD, O Gray circle $p<0.001$ versus standard $H D,{ }^{*} p<0.001$ versus $\% \Delta B V$ value at the end of $H D$ in standard $H D, \% \Delta B V$, relative change in blood volume; $H D$, hemodialysis, BV-UFC, blood volume change- guided ultrafiltration control

HD were significantly fewer $(-12.1 \pm 4.8 \%, p<0.001$ vs. standard HD). The suppression of changes in $\% \Delta B V$ at the last phase of HD in HD with BV-UFC would be associated with the prevention of symptomatic IDH episodes, which might result in the significant difference in the number of interventions for symptomatic IDH episodes during the last $1 \mathrm{~h} \mathrm{HD}$ compared with standard HD. Furthermore, in patients with chronic kidney disease, sympathetic nerve activity was reportedly higher than that in healthy control and further increased according to the decrease in extracellular volume [29]. In addition, sympathetic hyperactivity in patients undergoing short daily HD was significantly suppressed by the decrease in the magnitude of fluid fluctuation [30]. Therefore, the relief of a relative BV reduction, which means less fluid fluctuation, in HD with BV-UFC may contribute to the suppression of the sympathetic hyperactivity.

Regarding the meaning of the setting in UF rate divided into four parts during HD with the BV-UFC system, a constant UF rate period at first phase was set to confirm the stability in systemic BP under the same condition in standard HD. As a second phase, higher UF rate period would be expected to be easily removed excessive body fluid at the early phase of HD therapy. Furthermore, an automatic UF rate- adjustment period was set under the adjustment along the target $\% \triangle B V$ value to prevent the excessive $\% \triangle B V$ reduction during the middle to last phase of HD session. Finally, an automatic constant UF rate period was set to reach the dry weight at the end of HD during the last $20 \mathrm{~min}$ of $\mathrm{HD}$ session. Therefore, determination of two indices (UF rates during the higher UF rate period and the target $\% \triangle B V$ value during the automatic UF rate- adjustment period) was necessary before HD initiation in HD with BV-UFC. Before this study, the values in each patient were determined by observing hemodynamic stability during the run-in period. In standard HD with a constant UF rate, the recommended maximum UF rate is $\leq 15 \mathrm{~mL} /(\mathrm{kg} \cdot \mathrm{h})$ [31, 32]. However, in patients with IDH, removing more fluid during the first hour of $\mathrm{HD}$ and reducing the rate later were recommended under the concept of UF profiling control [33, 34] because of the higher rates of plasma refilling in response to UF at the early phase of the HD session, particularly within $1 \mathrm{~h}$ after the HD session [34]. In this study, UF rate during the higher UF rate period in HD with BV-UFC was 15.7 $\pm 4.2 \mathrm{~mL} /(\mathrm{kg} \cdot \mathrm{h})$. Thereafter, the $\% \triangle B V$ value within the automatic UF rate- adjustment period, on average, was set at $-4.0 \%$ during $150 \mathrm{~min}$. To reach the dry weight in standard HD with constant UF rates, the $\% \triangle B V$ range had been proposed previously [11]. Based on this report, at the end of $4 \mathrm{~h} \mathrm{HD}$ session, $\% \triangle B V$ per the percent change in body weight during HD was recommended from $-1.75 \%$ to $-3.73 \%$ [11]. In this study, dry weight was $61.3 \mathrm{~kg}$ and the residual UFV at the initiation of the automatic UF rate- adjustment period was $1.9 \mathrm{~L}$, which was equivalent to $3.10 \%$ of the percent change in body weight. Therefore, recommended $\% \triangle B V$ range during this period was calculated from $-3.39 \%$ to $-7.23 \%$. In this study, assumed $\% \triangle B V$ range during this period to prevent the excessive BV reduction was relatively low level compared with that previously recommended in standard HD.

In HD with BV-UFC, the UF rates were continuously changing along with the $\% \triangle B V$ changes during the automatic UF rate- adjustment period, which had been set before HD, and the UFV during this period cannot be strictly determined. Therefore, one of our major concerns was whether a delay in achieving the target UFV at the end of HD occurs in HD with BV-UFC. Being overweight at the end of HD by $\geq 0.3 \mathrm{~kg}$ was independently associated with an increased long-term risk of all-cause and cardiovascular mortality in patients undergoing HD 
[35]. Therefore, achievement of the target UFV at the end of HD was defined as within $\pm 0.3 \mathrm{~kg}$ of the dry weight in this study. As a result, no significant differences were found in HD sessions with a delay in achieving the target UFV between HD with BV-UFC and standard HD.

This study had several limitations. First, the sample size was relatively small. Second, the setting of the higher UF rate and $\% \triangle B V$ decrease during the automatic UF rate-adjustment period in each patient may have differences because these values were determined based on the hemodynamic stability during HD at the discretion of each hospital. Third, because HD therapy was crossed over between standard HD and HD with BV-UFC as the first and second HD sessions during this study, the therapeutic effect of HD with BV-UFC might not reach the steady state throughout the observation in this study. Therefore, it might be considered that this study could not correctly evaluate the therapeutic benefits of $\mathrm{HD}$ with BV-UFC, including BP stability during HD. Furthermore, the gradients between serum sodium and dialysate sodium levels, which were associated with body- fluid movement between intracellular and extracellular fluids, and body and dialysate temperatures are important factors in preserving hemodynamic stability during HD [36]. However, in this study, serum sodium levels were confirmed at limited times, and body and dialysate temperature were not recorded throughout this study. Therefore, we cannot directly comment on the influences of sodium gradients between blood and dialysate, as well as those of the body and dialysate temperatures on hemodynamic stability during HD. Therefore, additional studies are needed to confirm the therapeutic effect of HD with BV-UFC in detail in the future.

\section{Conclusion}

HD with BV-UFC did not reduce the prevalence of IDH compared with standard HD. The relief of a relative BV reduction at the end of HD may be beneficial in patients undergoing HD with BV-UFC.

\section{Acknowledgments}

We thank the study participants and gratefully acknowledge the contribution of the members of the BV-UFC Study Group.

BV-UFC Study Group members: Hideyuki Hayasaka, Masaya Kofuji, Megumi Ichiyanagi, Ryosuke Motegi, Tomohiro Yamasaki, Mariko Fueki, Sojiro Imai, Katsuo Iguchi, Tatsuya Kamimura, Noriko Wada, Mayumi Ueno, Sanae Okamoto, Yoshio Kaku, Nobuhiko Aida, Tomoya Murakami, and Kazuhiko Okuzumi.

\section{Authors' contributions}

$\mathrm{SO}, \mathrm{NH}$ and $\mathrm{KT}$ conceived and designed this study. SO, KI, TU, KT, SK, TS, KH $\mathrm{HM}, \mathrm{YU}, \mathrm{TH}, \mathrm{Cl}, \mathrm{OI}, \mathrm{KY}, \mathrm{YM}$ and $\mathrm{KT}$ performed this study. SO and $\mathrm{KI}$ analyzed the data. YM, NH and KT supervised the data collection and manuscript preparation. SO and $\mathrm{KI}$ drafted the manuscript. All authors read and approved the final manuscript.

\section{Funding}

The authors declare that there is no funding related to this manuscript. However, Nikkiso Corporation provided support in the form of covering costs required for this study. Nikkiso Corporation had no role in study design, data collection, analysis, decision to publish, or manuscript preparation.

Availability of data and materials

All data analyzed during this study are included in this published article.

\section{Ethics approval and consent to participate}

This study was registered at the University Hospital Medical Information Network (study No. UMIN000024670, date of registration: December 1, 2016) in Japanese Primary Registry Network; approved by the institutional review board of Saitama Medical Center, Jichi Medical University, Japan (RINS 16003); the study was conducted in accordance with the Declaration of Helsinki (2004 Tokyo revision). All patients signed informed consent forms before participation.

\section{Consent for publication}

For publication of this study, agreement was obtained from each patient

\section{Competing interests}

Nikkiso Corporation provided support in the form of covering costs required for this study. There are no patents, products in development associated with this study to declare.

$\mathrm{NH}$ is working as an associate editor of this journal. $\mathrm{NH}$ did not involve in the reviewing process of this article.

\section{Author details}

${ }^{1}$ Division of Nephrology, First Department of Integrated Medicine, Saitama Medical Center, Jichi Medical University, 1-847 Amanuma-cho, Omiya-ku, Saitama 330-8503, Japan. ²Department of Clinical Engineering, Saitama Medical Center, Jichi Medical University, Saitama, Japan. ${ }^{3}$ Department of Clinical Engineering, Hara Genitourinary Hospital, Hyogo, Japan. ${ }^{4}$ Department of Clinical Engineering, Minami-uonuma City Hospital, Niigata, Japan. ${ }^{5}$ Department of Clinical Engineering, Mooka Kumakura Clinic, Tochigi, Japan. ${ }^{6}$ Department of Clinical Engineering, Mooka Medical Clinic, Tochigi, Japan.

${ }^{7}$ Department of Nephrology, Mooka Medical Clinic, Tochigi, Japan.

${ }^{8}$ Department of Nephrology, Mooka Kumakura Clinic, Tochigi, Japan.

${ }^{9}$ Department of Nephrology, Hara Genitourinary Hospital, Hyogo, Japan.

${ }^{10}$ Department of Blood Purification, Tokyo Women's Medical University,

Tokyo, Japan. ${ }^{11}$ Department of Internal Medicine, Minami-uonuma City

Hospital, Niigata, Japan.

Received: 4 August 2020 Accepted: 7 October 2020

Published online: 17 October 2020

References

1. Daugirdas JT. Pathophysiology of dialysis hypotension. Am J Kidney Dis. 2001;38:S11-7.

2. Rho M, Perazella MA, Parikh CR, Peixoto AJ, Brewster UC. Serum vasopressin response in patients with intradialytic hypotension: a pilot study. Clin J Am Soc Nephrol. 2008;3:729-35.

3. Hur E, Usta M, Toz H, Asci G, Wabel P, Kahvecioglu S, et al. Effect of fluid management guided by bioimpedance spectroscopy on cardiovascular parameters in hemodialysis patients: a randomized controlled trial. Am J Kidney Dis. 2013;61:957-65.

4. Gunal Al, Duman S, Ozzkahya M, Toz H, Asci G, Akcicek F, et al. Strict volume control normalizes hypertension in peritoneal dialysis patients. Am J Kidney Dis. 2001;37:588-93.

5. Flythe JE, Xue H, Lynch KE, Curhan GC, Brunelli SM. Association of mortality risk with various definitions of intradialytic hypotension. J Am Soc Nephrol. 2015;26:724-34

6. Dekker MJ, Marcelli D, Canaud BJ, Carioni P, Wang Y, Grassmann A, et al. Impact of fluid status and inflammation and their interaction on survival: study in an international hemodialysis patient cohort. Kidney Int. 2017;91: 1214-23.

7. Steuer RR, Harris DH, Weiss RL, Biddulph MC, Conis JM. Evaluation of a noninvasive hematocrit monitor: a new technology. Am Clin Lab. 1991;10: $20-2$. 
8. Johner C, Chamey PW, Schneditz D, Kramer M. Evaluation of an ultrasonic blood volume monitor. Nephrol Dial Transplant. 1988;13:2098-103.

9. Mancini E, Santoro A, Spongano M, Paolini F, Rossi M, Zucchelli P. Continuous on-line optical absorbance recording of blood volume changes during hemodialysis. Art Organs. 1993;17:691-4.

10. Paolini F, Mancini E, Bosetto A, Santoro A. Hemoscan: a dialysis machineintegrated blood volume monitor. Int J Artif Organs. 1995;18:487-94.

11. Yoshida I, Ando K, Ando Y, Ookawara S, Suzuki M, Furuya H, et al. A new device to monitor blood volume in hemodialysis patients. Ther Apher Dial. 2010;14:560-5

12. Thijissen S, Kappel F, Kotanko P. Absolute blood volume in hemodialysis patients: why is it relevant, and how to measure it? Blood Purif. 2013;35:63-71.

13. Song JH, Park GH, Lee SY, Lee SW, Lee SW, Kim MJ. Effect of sodium balance and the combination of ultrafiltration profile during sodium profiling hemodialysis on the maintenance of quality of dialysis and sodium and fluid balances. J Am Soc Nephrol. 2005;16:237-46.

14. Ramunni A, Brescia P, Ranieri G, Ria R, Coratelli P. Can a decreasing ultrafiltration profile affect the dialytic dose administered? Ther Apher Dial. 2006;10:463-6

15. Donauer J, Kolblin D, Bek M, Krause A, Bohler J. Ultrafiltration profiling and measurement of relative blood volume as strategies to reduce hemodialysis-related side effects. Am J Kidney Dis. 2000;36:115-23.

16. Zhou YL, Liu HL, Duan XF, Yao Y, Sun Y, Liu Q. Impact of sodium and ultrafiltration profiling on haemodialysis-related hypotension. Nephrol Dial Transplant. 2006;21:3231-7.

17. Kuipers J, Oosterhuis JK, Krijnen WP, Dasselaar JJ, Gaillard CAJM, Westehuis $\mathrm{R}$, et al. Prevalence of intradialytic hypotension, clinical symptoms and nursing interventions - a three-months, prospective study of 3818 haemodialysis sessions. BMC Nephrol. 2016;17:21. https://doi.org/10.1186/ s12882-016-0231-9.

18. Shin CJ, Tarng DC, Ynag WC, Ynag CY. Parathyroidectomy reduced intradialytic hypotension in hemodialysis patients with secondary hyperparathyroidism. Kidney Blood Press Res. 2013;37:323-31.

19. Katalinic L, Krtalic B, Jelakovic B, Basic-Jukic N. The unexpected effects of $L$ carnitine supplementation on lipid metabolism in hemodialysis patients. Kidney Blood Press Res. 2018;43:1113-20.

20. Converse RL Jr, Jacobsen TN, Jost CM, Toto RD, Grayburn PA, Obregon TM, et al. Paradoxical withdrawal of reflex vasoconstriction as a cause of hemodialysis-induced hypotension. J Clin Invest. 1992;90:1657-65.

21. Santoro A, Mancini E, Basile C, Amoroso L, Giulio SD, Usberti M, et al. Blood volume controlled hemodialysis in hypotension-prone patients: a randomized, multicenter controlled trial. Kidney Int. 2002;62:1034-45.

22. Dasselaar JJ, Huisman RM, de Jong PE, Burgerhof GM, Franssen CM. Effects of relative blood volume-controlled hemodialysis on blood pressure and volume status in hypertensive patients. ASAIO J. 2007:53:357-64.

23. Gagrielli D, Krystal B, Katzarski K, Youssef M, Hachache T, Lopot F, et al. Improved intradialytic stability during haemodialysis with blood volumecontrolled ultrafiltration. J Nephrol. 2009;22:232-40.

24. Leung KCW, Quinn RR, Ravani P, Duff H, MacRae JM. Randomized crossover trial of blood volume monitoring-guided ultrafiltration biofeedback to reduce intradialytic hypotensive episodes with hemodialysis. Clin J Am Soc Nephrol. 2017;12:1831-40.

25. Antlanger $M$, Josten $P$, Kammer $M$, Exner I, Lorenz-Turnheim K, Eigner $M$ et al. Blood volume-monitored regulation of ultrafiltration to decrease the dry weight in fluid-overloaded hemodialysis patients: a randomized controlled trial. BMC Nephrol. 2017;18:238.

26. Hecking M, Schneditz D. Feedback control in hemodialysis - much ado about nothing. Clin J Am Soc Nephrol. 2017;12:1730-2.

27. Javed F, Savkin AV, Chan GSH, Middleton PM, Malouf P, Steel E, et al. Model predictive control of relative blood volume and heart rate during hemodialysis. Med Biol Eng Comput. 2010;48:389-97.

28. Ookawara S, Miyazawa H, Ito K, Ueda Y, Kaku Y, Hirai K, et al. Blood volume changes induced by low-intensity intradialytic exercise in long-term hemodialysis patients. ASAIO J. 2016;62:190-6.

29. Klein $\mathrm{H}$, Ligtenberg G, Neumann J, Oey L, Koomans HA, Blankestijn PJ. Sympathetic nerve activity is inappropriately increased in chronic renal disease. J Am Soc Nephrol. 2003;14:3239-44

30. Zilch O, Vos PF, Oey PL, Cramer MJM, Ligtenberg G, Koomans HA, et al. Sympathetic hyperactivity in haemodialysis patients is reduced by short daily haemodialysis. J Hypertens. 2007;25:1285-9.
31. KDOQI Workgroup. K/DOQI clinical practice guidelines for cardiovascular disease in dialysis patients. Am J Kidney Dis. 2005;45:S1-S153.

32. Hirakata H, Nitta K, Inaba M, Shoji T, Fujii H, Kobayashi S, et al. Japanese Society for Dialysis Therapy guidelines for management of cardiovascular disease in patients on chronic hemodialysis. Ther Apher Dial. 2012;16:387-435.

33. Agarwal R. How can we prevent intradialytic hypotension? Curr Opin Nephrol Hypertens. 2012;21:593-9.

34. limura O, Tabei K, Nagashima H, Asano Y. A study on regulating factors of plasma refilling during hemodialysis. Nephron. 1996;74:19-25.

35. Movilli E, Camerini C, Gaggia P, Zubani R, Feller P, Poiatti P, et al. Magnitude of end-dialysis overweight is associated with all-cause and cardiovascular mortality: a 3-year prospective study. Am J Nephrol. 2013;37:370-7.

36. Kooman J, Basci A, Pizzarelli F, Canaud B, Haage P, Fouque D, Konner K, et al. EBPG guideline on haemodynamic instability. Nephrol Dial Transplant. 2007:22:ii22-44.

\section{Publisher's Note}

Springer Nature remains neutral with regard to jurisdictional claims in published maps and institutional affiliations.

Ready to submit your research? Choose BMC and benefit from:

- fast, convenient online submission

- thorough peer review by experienced researchers in your field

- rapid publication on acceptance

- support for research data, including large and complex data types

- gold Open Access which fosters wider collaboration and increased citations

- maximum visibility for your research: over $100 \mathrm{M}$ website views per year

At $\mathrm{BMC}$, research is always in progress.

Learn more biomedcentral.com/submissions 